\title{
Genetic tools to mitigate the environmental impact of milk production systems: Experience with a multi-point individual cow methane measurement system \\ E. Negussie, A,-E. Liinamo, E. A. Mäntysaari, M. Lidauer \\ MTT Agrifood Research, Biotechnology \& Food Research, Biometrical Genetics, 31600 Jokioinen, Finland
}

\begin{abstract}
Methane is one of the most potent greenhouse gases with about 21 times the Global Warming Potential (GWP) of carbon dioxide. Methane emission by dairy cows is not only a significant concern for the environment but also represent a loss of energy for milk production. Dairy cows lose 6 to $12 \%$ of feed energy and $95 \%$ of which is released through mouth as eructated methane. The most important avenue for reducing methane emissions from dairy systems is by improving the productivity and efficiency of dairy cows, through better nutrition and genetics.

Attempts to reduce the ecological foot print of milk production require a sound understanding of the genetic basis of methane emissions. This requires reliable techniques for the measurement of methane output from individual cows. Enteric methane from ruminants is an important but often difficult source to quantify on an individual basis. So far, many of the available measurement techniques are either slow, expensive, labor intensive and are unsuitable for large scale measurements which is a prerequisite for genetic studies. This study evaluated a non-invasive Photoacoustic Infrared Spectroscopy (PAS) technique for quantifying enteric methane output from the breath of individual dairy cows.

The study was conducted at MTT experimental dairy herd in Minkiö. A total of about 40 firstlactation Finnish Ayrshire cows were included. Individual cow methane, carbon dioxide (CO2), acetone, ammonia outputs were measured continuously over 3 weeks period using a multi-point PAS gas analyzer fitted to two feeding kiosks (sampling points). Whenever a cow visits a feeding kiosk, her breath was sampled and analyzed for the contents of the different gases. Measurements were made alternatively between the two sampling points and every other minute a gas was sampled and analyzed from each.

Records from continuous three days measurements were analyzed. There were about 6-14 repeated measurements on each of the different gasses per cow and a total of 1690 and 1908 measurements from sampling point 1 and 2, respectively. Ratio of $\mathrm{CH} 4: \mathrm{CO} 2$ is concentration independent and can be used to quantify methane output in dairy cows. Thus for each cow, $\mathrm{CH} 4: \mathrm{CO} 2$ ratios were calculated using measurements of these gasses. Basic statistical measures were calculated. Between and within individual variability were quantified and the repeatability of $\mathrm{CH} 4: \mathrm{CO} 2$ were estimated using the General Linear Models (GLM) procedure. The overall mean(sd) of $\mathrm{CH} 4: \mathrm{CO} 2$ from kiosk1 and 2 were $0.071(0.049)$ and $0.073(0.042)$ and the repeatability of $\mathrm{CH} 4: \mathrm{CO} 2$ were 0.56 and 0.57 for kiosk1 and 2, respectively. Repeatability sets the upper limit to heritability. Compared to other studies, repeatabilities from this study are on the higher side and suggest the suitability of the PAS for individual cow $\mathrm{CH} 4$ measurements that is a requisite in genetic studies.
\end{abstract}

\section{Key words:}

Dairy cows, Repeatability, Methane, $\mathrm{CH} 4: \mathrm{CO} 2$ ratio, Photoacoustic Infrared Spectroscopy 


\section{Introduction}

Livestock production is an integral part of many farming systems. Historically, environmental impacts of livestock production have been confined to more localized problems of overgrazing, desertification, and pollution of water courses from poor waste lands. To date, the environmental damage attributed to livestock and responsibilities for greenhouse gas emissions are the more recent and growing concerns (Moran and Eileen, 2011). Methane released to the atmosphere by domestic ruminant livestock represents the largest global source of methane which is a potent greenhouse gas that contributes to the global warming. Methane has about 21 times the Global Warming Potential of carbon dioxide

Finland is signatory to the Kyoto treaty on Climate change and has commitments to reduce its overall GHG emissions from the different sectors. Agriculture is an important sector of the Finnish economy and it is the third largest greenhouse gas emission source category. In Finland, methane emissions from enteric fermentation of dairy cattle account for more than $50 \%$ of the total domestic livestock emissions and stands as one of the significant contributors to the Finnish greenhouse gas budget. Besides, methane emission from dairy systems is not only an environmental hazard but it is also a loss of animal productivity. This is because enteric emission of methane represents a loss of carbon from the rumen and therefore an unproductive use of dietary energy (Hindrichsen et al. 2006). Dairy cows lose about 6 to $12 \%$ of their ingested energy and of which about $95 \%$ is released as eructated methane. Thus, mitigation of methane emission from dairy systems is required not only to help reduce Finland's Kyoto Protocol liabilities - but also to increase efficiency of dairy production.

The most important avenue for reducing methane emissions from dairy systems is by improving the productivity and efficiency of dairy cows, through better nutrition and genetics. Understanding the genetic and nutritional basis of dairy emissions is therefore essential. In this regard, between-animal variations in methane emission has been indicated (Schenkel et al. 2004; Hegarty et al. 2007) and may offer a novel opportunity to reduce emission of this greenhouse gas from domestic ruminants by phenotypic and genetic selection for low emissions. For instance, reduction of enteric methane emissions from livestock by selection for more feed-efficient animals based on their estimated breeding values (EBVs) will offer a novel way of reducing feed costs and methane production (Hegarty et al., 2007).

Direct selection for methane output requires accurate and large scale measurement of the gas from individual cows. Large variations have been postulated in methane emissions between animals at the same level of performance and diet. In trials with Friesian Jersey crossbreds herds, significant variation was found between cows for this phenotype (PGgRC 2004). Goopy and Hegarty (2004) identified some steers as 'high' and 'low' emitters on identical feed and feed intakes. In sheep, Robinson et al. (2010), reported large between individual variations in 1-hr methane measurement in an experiment involving 708 adult non-pregnant ewes. They found a repeatability of 0.3 and 0.53 with and without adjustment for body weights, respectively. However, so far information on the genetic basis of between-animal variation in methane emission and its heritability from dairy systems are lacking. Any attempt to reduce the ecological foot print of milk production via selection requires a sound understanding of the genetic basis of methane emission. However, the lack of reliable techniques for the measurement of methane output from large number of individual cows has been a hindrance to this. The ability to accurately measure methane output from individual cows is thus essential to gauge our ability to mitigate its emissions. So far, many of the available measurement techniques 
are either slow, expensive, labour intensive and are unsuitable for large scale measurements which is a prerequisite for genetic studies. The objective of this study was therefore to test the suitability of a non-invasive individual cow methane measurement system that is based on Photoacoustic Infrared Spectroscopy technique as a means to quantify the methane out put on the large scale.

\section{Material and methods}

The study was conducted at MTT experimental dairy herd in Minkiö. A total of about 40 firstlactation Finnish Ayrshire cows were included. The cows are part of the high genetic merit ASMO ET cows which are fed and managed similarly. Apart from all productive and functional traits, the individual feed intake of these cows are also regularly monitored and recorded during the early lactation phase. In the future, this will give ample opportunity for simultaneous recording of $\mathrm{CH} 4$ and other traits for subsequent analysis of genetic and phenotypic associations. Individual animal methane out put could be estimated from concentrations of $\mathrm{CH} 4$ and $\mathrm{CO} 2$ and their ratio in cow breath samples. Madsen et al. (2010) presented a simple, fast, reliable and cheap method to estimate the $\mathrm{CH} 4$ and $\mathrm{CO} 2$ concentrations in air near the animals combined with an estimation of the total $\mathrm{CO} 2$ production from information on intake of metabolizable energy or heat producing units. By using gas analysers to quantify the concentration of $\mathrm{CH} 4$ and $\mathrm{CO} 2$ gasses and $\mathrm{CH} 4: \mathrm{CO} 2$ ratios in the breath of cows it is possible to calculate the proportion of the carbon that is not metabolized to $\mathrm{CO} 2$, but excreted as $\mathrm{CH} 4$. For this accurate quantification of $\mathrm{CH} 4, \mathrm{CO} 2$ gasses, $\mathrm{CH} 4: \mathrm{CO} 2$ ratios and determining the repeatability of these measurements are essential. For this purpose, a non-invasive Photoacoustic Infrared Spectroscopy (PAS) gas analyzer has been selected and procured from the Finnish company GASERA Ltd. The F10 multi-gas analyzer is based on the principle of Photoacoustic Infrared Spectroscopy utilizing GASERA's patented ultra-sensitive cantilever sensor and pulsed IR source (with no mechanical chopper). It has high sensitivity with low sample volume (only few millilitres), suitable for the measurement of difficult gas mixtures (e.g., with high humidity) and requires no consumables (Figure 1).

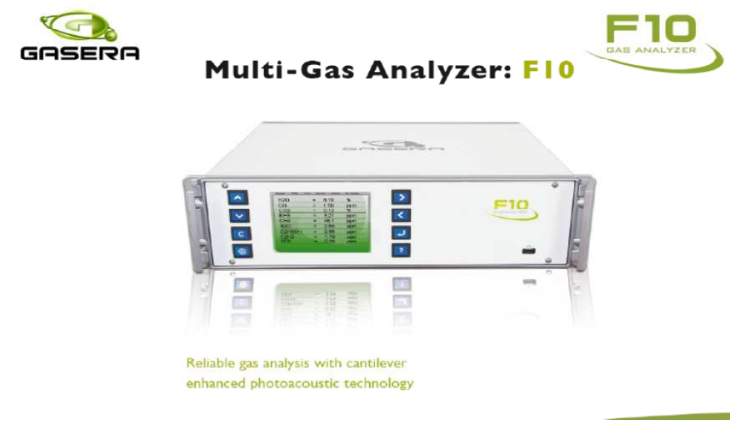

Figure 1. F10 Multi-gas analyzer from GASERA Ltd.

Using the F10 multi-gas analyzer, individual cow methane, carbon dioxide (CO2), acetone, ammonia outputs were measured continuously over 3 weeks period using a multi-point PAS gas analyzer fitted to two feeding kiosks (sampling points). Whenever a cow visits a feeding kiosk, her breath was sampled and analyzed for the contents of the different gases. Measurements were made alternatively between the two sampling points and every other minute a gas was sampled and analyzed from each. The two-point F10 multi-gas analyzer set-up and a cow in feeding kiosk 1 getting her concentrate supplement while the sampling and measurement of the gases are carried out is given in Figure 2. 


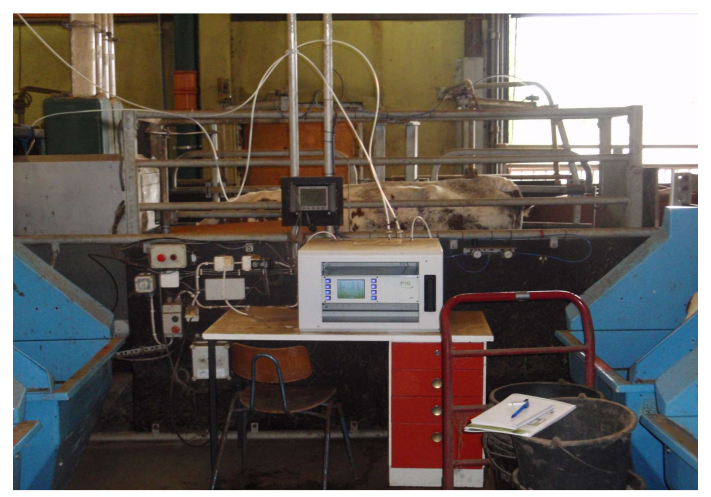

Figure 2. A two-point F10 Multi-gas analyzer set-up in operation with a cow in feeding kiosk getting her concentrate supplement while the gas sampling and measurements are made at the MTT Minkiö dairy barn.

Repeated records from continuous three days measurements on $\mathrm{CO} 2, \mathrm{CH} 4, \mathrm{NH} 3$, acetone and $\mathrm{CH} 4: \mathrm{CO} 2$ ratios from the two different sampling points were analyzed. The ratio of $\mathrm{CH} 4: \mathrm{CO} 2$ is concentration independent and could be used to quantify methane output in ruminants. The between and within individual variability were quantified and the repeatabilities were estimated using the General Linear Models (GLM) procedure.

\section{Results and discussion}

The suitability of a non-invasive gas analyzer that is based on Photoacoustic Infrared Spectroscopy (PAS) technique is being tested for identifying phenotypes essential for quantifying enteric methane output from the breath of individual dairy cows in a multi-point sampling setup.

Results from our preliminary analysis of the data shows that the mean $\pm \mathrm{SD} \mathrm{H} 2 \mathrm{O}, \mathrm{CO} 2, \mathrm{CH} 4$, Acetone and Ammonia concentrations in the breath of cows from sampling point1 (Kiosk1) were 20771(1759), 6801(4935), 591(232), 4.51(2.27), 1.52(1.12), 0.071(0.032), respectively. On the other hand mean $\pm \mathrm{SD} \mathrm{H} 2 \mathrm{O}, \mathrm{CO} 2, \mathrm{CH} 4$, Acetone and Ammonia concentrations in the breath of cows from sampling point2 (Kiosk2) were 18062(899), 3543(1381), 292(152), 4.41(2.13), $1.59(1.14), 0.073(0.036)$. The results clearly show some differences in the concentration of the gasses measured from the two different sampling points. One of the main reasons for this was the location of the two sampling points which were about 30 meters apart on different locations. In addition, the fact that the floor underneath kiosk1 was open while that of kiosk2 was closed resulted in higher background measurement concentrations to the former contributing to the differences to the concentrations of the gases measured from the two points in the data uncorrected for background concentrations. Surprisingly, the $\mathrm{CH} 4: \mathrm{CO} 2$ concentrations measured from the two sampling points were more similar with 0.071 and 0.073 from point 1 and point 2 respectively substantiating the fact that $\mathrm{CH} 4: \mathrm{CO} 2$ is concentration independent and a promising measure for the quantification of methane out put from ruminant animals.

One of the main objectives of this study was to develop a phenotype that is consistent and repeatable to enable us the quantification of methane out put in ruminants as described in Madsen et al. (2010). They described that with information on live weight, milk production and feed intake the heat production and CO2 output (Pedersen et al. 2008; Madsen et al. 2010) of a cow can be quantified. If the $\mathrm{CH} 4: \mathrm{CO} 2$ ratios are known, then the total $\mathrm{CH} 4$ production 
of a cow can also be calculated (Madsen et al., 2010). The main purpose in this study was to generate $\mathrm{CH} 4: \mathrm{CO} 2$ phenotype that is possible to record in a precise and repeatable way.

The repeatability of $\mathrm{CH} 4, \mathrm{CO} 2$ and $\mathrm{CH} 4: \mathrm{CO} 2$ ratios were calculated from continuous three days measurements. The between and within individual animal variability were quantified and the repeatability of the three phenotypes $(\mathrm{CO} 2, \mathrm{CH} 4$ and $\mathrm{CH} 4: \mathrm{CO} 2)$ were estimated using the General Linear Models (GLM) procedure (random option). The overall mean(sd) of CH4:CO2 ratios from kiosk1 and 2 were $0.071(0.049)$ and $0.073(0.042)$ and the repeatability of $\mathrm{CH} 4: \mathrm{CO} 2$ ratios were 0.55 and 0.57 for kiosk1 and 2, respectively. Although slightly lower, the repeatability estimates for $\mathrm{CH} 4$ and $\mathrm{CO} 2$, respectively ranged from 0.54 to 0.57 and from 0.53 to 0.57 .

Repeatability is an important statistical concept that measures the consistency of trait during repeated measuremnts and allows predicting future performance based on measurements (Gonzalez et al. 2010). To obtain reliable measurements of methane output from ruminants with the above mentioned method, a clear understanding of the repeatability of the $\mathrm{CH} 4: \mathrm{CO} 2$ phenotype in the population under consideration is essential. However, so far not much has been reported on this subject from diary systems. For instance, McCourt et al. (2005) and Grainger et al. (2007) reported repeatability of 0.17 and 0.18 for $\mathrm{CH}_{4}$ production. Their estimates were from study involving the Sulphur hexafluoride Tracer Technique $\left(\mathrm{SF}_{6}\right)$ and a whole animal respiration chamber. In these studies, only 16 animals were measured Grainger et al. (2007) and in McCourt et al. (2005) studies $\mathrm{CH}_{4}$ production was measured on beef cattle steers.

Recently Lassen et al. (2011) reported a study with the aim of estimating individual cow differences in $\mathrm{CH}_{4}$ production. In their study, individual methane $\left(\mathrm{CH}_{4}\right)$ output was recorded repeatedly on 93 dairy cows during milking in an automatic milking system (AMS). They have measured $\mathrm{CH} 4$ and $\mathrm{CO} 2$ concentrations via a portable air-sampler and analyzer unit that is based on Fourier Transformed Infrared (FTIR) detection and involved 50 Danish Holsteins and 43 Jerseys. For median measurements, they reported repeatability of $\mathrm{CH} 4: \mathrm{CO} 2$ ratio of 0.37 for Holsteins and 0.33 for Jerseys whilst the repeatability of $\mathrm{CH} 4$ and $\mathrm{CO} 2$ gasses respectively from the same median measurements were 0.33 and 0.45 for Holsteins and 0.37 and 0.38 for Jerseys. The repeatability estimates from our study is higher than most reported in literature so far. Our estimates of the about 0.57 for $\mathrm{CH} 4: \mathrm{CO} 2$ ratios and 0.55 and 0.54 for $\mathrm{CH} 4$ and $\mathrm{CO} 2$ gasses are higher than 0.32 reported for 1 -hr methane measurements from non-pregnant adult sheep in Australia (Robinson et al. 2010) and 0.33 and 0.37 reported for Danish Holsteins and Jerseys, respectively. The reasons for the high repeatability form our study could be due to the more uniform and similarly treated first-lactation Finnish Ayrshire population used in the study, the effects included in the model and the accuracy and efficiency of the multi-gas analyser used for the quantification of the concentration of gases from the breath of individual cows. The results reported here are from three days continuous measurements of 40 first lactation cows. It is therefore planned to verify the current estimates on a large data and preferably involving more animals in the future. 


\section{Conclusion}

In this study the suitability of a non-invasive gas analyzer that is based on Photoacoustic Infrared Spectroscopy (PAS) technique was tested for identifying phenotypes i.e. CH4, $\mathrm{CO} 2$, and $\mathrm{CH} 4: \mathrm{CO} 2$ ratio that are essential for quantifying enteric methane output from the breath of individual dairy cows in a multi-point sampling setup. Results obtained indicate that the mean $\mathrm{CH} 4: \mathrm{CO} 2$ is about 0.071 and has a repeatability ranging from 0.55-0.59 which is slightly higher than that estimated for $\mathrm{CH} 4$ or $\mathrm{CO} 2$. Repeatability sets the upper limit to heritability. The repeatability from this study that is higher than so far reported in literature suggest the suitability of the PAS technique for quantification of $\mathrm{CH} 4$ out put from individual cows in a large scale that is a requisite for future genetic studies of dairy system emissions. In the future, results from F10 measurements will be validated against the measurements from an open circuit indirect calorimeter of same cows.

\section{References}

Gabriel G. Gonza'lez, Katherina B. Brokordt, Federico E. Winkler. 2010. Repeatability of physiological traits in juvenile Pacific abalone, Haliotis discus hannai. Mar Biol (2010) 157:2195-2203.

Grainger, C., T. Clarke, S.M. McGinn, M.J. Auldist, K.A. Beauchemin, M.C. Hannah, G.C.Waghorn, H. Clark and R.J. Eckard. 2007. Methane emissions from dairy cows measured using the sulfur hexafluoride (SF6) tracer and chamber techniques. J. Dairy Sci. 90:2755-2766

Goopy JP, Hegarty RS (2004) Repeatability of methane production in cattle fed concentrates and forage diets. J Anim Feed Sci 13:75-78

Hegarty R.S., Goopy, J. P., Herd, R. M., McCorkell, B. 2007. Cattle selected for lower residual feed intake have reduced daily methane production. J. Anim. Sci. $85: 1479-1486$

Hegarty, R.S., and J.C. McEwan. 2010. Genetic opportunities to reduce enteric methane emissions from ruminant livestock. In: Proc. 9th World Congress in Genetics Applied to Livestock Production. Book of Abstracts. Abstract no. 515.

Hindrichsen, I.K., Wettstein, H.-R., Machmuller, A., Kreuzer, M. 2006. Methane emission, nutrient degradation and nitrogen turnover in dairy cows and their slurry at different milk production scenarios with and without concentrate supplementation. Agriculture, Ecosystems and Environmen. 113:150-161.

Lassen J. 2011. Animal variation in methane emission from breath of Danish Red, Holstein and Danish Jersey. In proceedings of the AnGR-NordicNET workshop on "Effects of climate change on primary industries in the Nordic countries" on 10.11.2011, in Uppsala, Sweden

McCourt, A., T. Yan, C.S. Mayne and M.G. Porter. 2005. Prediction of methane output in beef cattle from indirect respiration calorimetry data. In: C.R. Soliva, J. 
Takahashi and M. Kreuzer, Editors, Proc. 2nd Int. Conf. Greenhouse Gases and Anim. Agric, ETH-Centre, Zurich, Switzerland, Publ. Series, Inst. Anim. Sci. 27:405-408.

Madsen, J., B.S. Bjerg, T. Hvelplund, M.R. Weisbjerg, and P. Lund. 2010. Methane and carbon dioxide ratio in excreted air for quantification of methane production in ruminants. Livest. Sci.129:223-227.

Moran, D. and Wall, E. 2011. Livestock production and greenhouse gas emissions: Defining the problem and specifying solutions. Animal Frontiers. 1:19-25.

Pedersen, S., Blanes-Vidal, H. Jorgensen, H., A. Chwalibog, A. Haeussermann, M.J.W. Heetkamp, and A.J.A. Aarnink. 2008. Carbon dioxide production in animal houses: A literature review. Agricultural Engineering International: CGIR Ejournal. Manuscript BC 08 008, Vol X. December 2008. 19 pp.

PGgRC (2004) The pastoral greenhouse gas research strategy. Annual report to the crown on progress. Pastoral Greenhouse Gas Research Consortium, Wellington, New Zealand.

Robinson, D.L., J.P. Goopy, R.S. Hegarty, and P.E. Vercoe. 2010. Repeatability, animal and sire variation in 1-hr methane emissions and relationship with rumen volatile fatty acid concentrations. In: Proc. 9th World Congress in Genetics Applied to Livestock. Book of Abstracts. Abstract no 712.

Schenkel, F.S., Miller, S.P. and Wilton, J.W. 2004. Genetic parameters and breed differences for feed efficiency, growth and body composition traits of young beef bulls. Can. J. Anim. Sci. 84:177-185. 